\title{
The synthesis of dynamic and historical data on marine populations and communities; putting dynamics into the Ocean Biogeographical Information System (OBIS)
}

Ransom A. Myers

Dalhousie Unizersity - Halifax, Nowa Scotia Canada

\section{Introduction}

The understanding of marine ecosystems requires long-term historical data. Unfortunately, population dynamics data of marine species are much like Hobbes' view of the life of primitive humans: nasty, brutish, and short. The data are nasty because the estimation error is often large and there are frequently gross errors in the recording or transcription of the data. The data are brutish as they are often unstandardized, in unpublished government reports, not in a computer readable format, and organized in ways that make them difficult, if not impossible, to comprehend. The data are short, as the collection of population dynamics data for marine species usually involves a tremendous investment of time and resources. And yet, to answer many of the critical questions in the conservation, optimal management, and understanding of marine ecosystems requires the synthesis of historical and dynamic data from diverse sources and species. As an example, without the analysis of a very large data set, we would not have known that a large distinctive marine fish had been lost from much of its range (Casey and Myers, 1998).

There is thus a pressing need to archive, disseminate and synthesize data on the dynamics of marine populations and communities in order to understand and deal with massive human impacts (overfishing, species invasions, climate change) currently occurring (Goldberg, 1995; Cohen and Carlton, 1998; Ruiz et al., 1997). At present, the scattered nature of the informa- tion makes it almost impossible for an individual researcher to collate enough of the data to come to broad, scientifically valid conclusions. Coupled with the paucity of historical data, it is almost impossible to model and understand changes at a population level, much less a community level (Dayton et al., 1995). The historical information is of particular importance in determining the true productivity that marine systems may be able to sustain, and the loss of historical data results in the "shifting baseline syndrome"(Pauly, 1995).

Here, I will describe my attempts to compile and synthesize much of the world population dynamics data on exploited fish and aquatic invertebrate species as well as describe future plans for extending the database. The
At present, the scattered nature of the information makes it almost impossible for an individual researcher to collate enough of the data to come to broad, scientifically valid conclusions. basic idea of this research is that a synthetic approach will allow questions to be addressed that in the past were simply beyond our grasp. The fundamental goals of the project are: (1) to make dynamic data available for research and education; (2) to establish a structure that allows data to be accumulated in a standardized form, and so that it can be easily used by other researchers; (3) to preserve historical data so that changes can be detected; (4) to allow the use of metaanalytic techniques to improve our understanding of population and community dynamics; and (5) to provide inputs and tests for ecosystem models.

\section{Data}

The database contains time-series data on over 700 
populations, comprising 160 species, from around the world that describe changes in abundance, natural variability in survival, and fishing mortality. The database can be found at: http://fish.dal.ca/welcome.html. The geographic locations of the fish populations presently contained in this database are shown in Figure 1.

The goal of this project, however, goes far beyond the simple compilation of data; we standardize the data so that they can be analyzed in a systematic fashion. They can be used to address critical and fundamental questions that could not previously be addressed. For example, the simple question of how maximum population growth rate or carrying capacity varies for well known species, e.g. cod, could not be addressed without a meta-analytic approach to the problem (Myers et al., 1997).

\section{Design of a Global Database}

At present, most assessments of fish and other species are not in a form that are readily transferable and comprehensible among regions. The situation in which data are collected by individual researchers is even worse. With the development of a global standard, it would be a relatively easy matter for assessments and surveys of marine life to be stored and retrieved for worldwide comparisons and meta-analyses. Although data on relative abundance are important, it is much more useful to have data on absolute abundance, since they can be used to estimate key demographic parameters, like maximum reproductive rate and carrying capacity (Myers et al., 1999a; Myers et al., 1999b). The ability to estimate key demographic parameters is fundamental to the design of the database.

Recent uses of the database include: addressing extinction in the ocean (Casey and Myers, 1998), determining recovery rates of cod stocks (Myers et al., 1997), understanding why fish populations collapse and recover (Hutchings and Myers, 1994; Myers, Hutchings,

Figure 1.

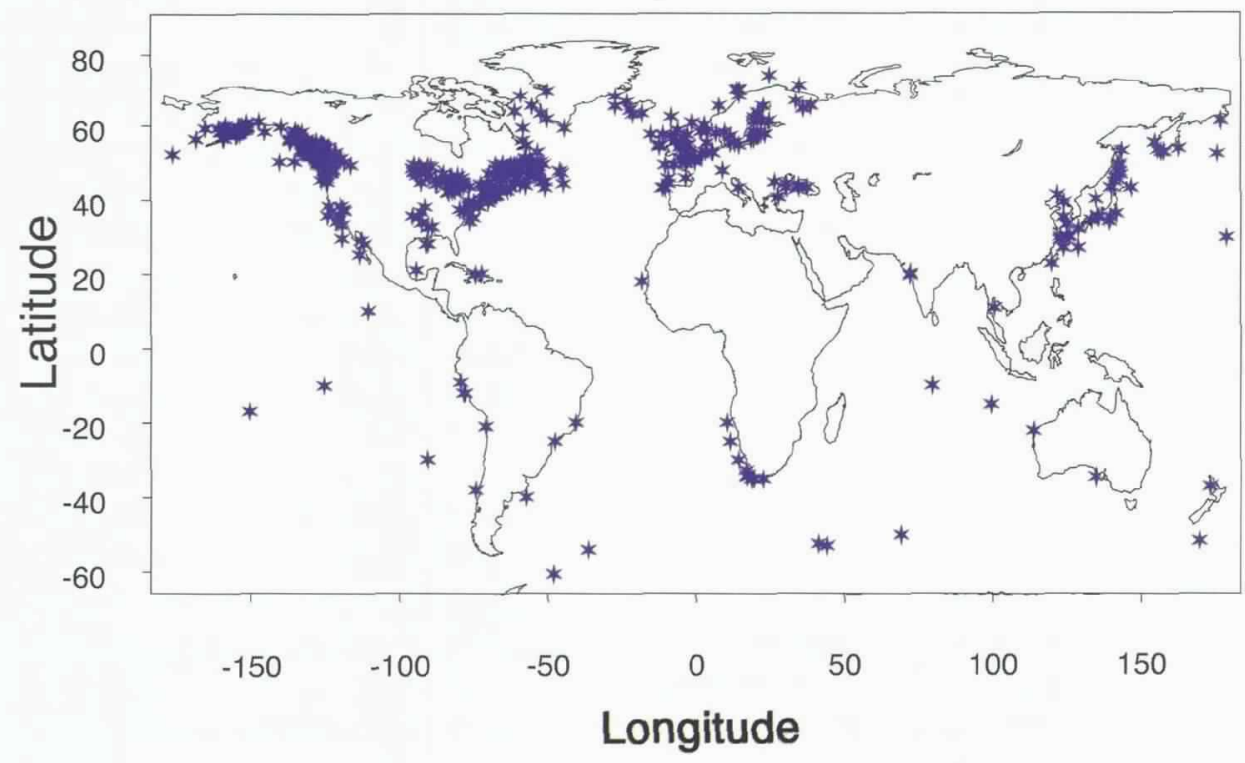

and Barrowman, 1996, 1997; Hutchings, 2000), completing a meta-analysis of 80 sockeye salmon population time-series to improve management of the species (Myers et al., 1997, 1998), developing extinction models of endangered coho salmon stocks (Bradford et al., 2000), calculating management reference points for U.S. fish stocks (Myers et al., 1994) and determining the behavior of overexploited stocks at low population sizes (Myers et al., 1995). In addition, the management of the west coast groundfish will be determined partially from the results of a meta-analysis of the maximum reproductive rates estimated from spawner-recruit time series in the database (Myers et al., 1999b).

The database can be easily expanded for other commercially exploited fish and invertebrates by simply getting national and international agencies to output their data in a standard format, and automatically transferring the data to a central location. Researchers around the world are quite willing to cooperate on this endeavor, and we will work with assessment scientists around the world to develop a standard output, containing the critical parameters needed. From this core database, we will enhance existing software that has been written to standardize the data, and to carry out various meta-analyses.

\section{The Global Data Base and the use of Meta-Analysis}

Although the need for a synthetic approach to the study of fish population dynamics has long been recognized (Beverton and Holt, 1959; Pauly, 1980; Brander, 1994; Ricker, 1954; Cushing, 1971); there are several reasons why a synthesis is only possible now. First, modern assessment methods have allowed detailed analysis of many more stocks to be completed. Second, the now widespread use of research surveys allows these assessments to be more accurate, at least in theory. Finally, and most importantly, new statistical and analytical methods allow analyses and computations that simply were not possible a few years ago. For example, the use of Markov chain Monte Carlo methods allow Bayesian methods to be easily implemented on problems that would have been impossible quite recently. Similarly, the widespread availability of high quality computer programs for mixed and variance components models allow these methods to be easily applied.

Meta-analysis is the term used to describe quantitative methods for combining evidence across studies. 
In the work I describe here, results will be combined across populations instead of experiments. That is, I will treat the time-series of each population as a realization of a natural experiment, and combine results across populations. The use of meta-analysis is motivated by the lack of long term data for any one population. We may never have reliable data on over 100 generations for a natural fish population, and yet this is what we need to make reliable statistical inferences. By combining estimates for many populations, we may be able to use much shorter time series to reach reliable conclusions. It is critical that appropriate statistical methods be used to combine data from many populations. There are many subtle pitfalls if multiple studies are combined in a naive fashion. For example, when studies are being reviewed, it is often of interest to determine how often a given hypothesis is statistically significant. This procedure is known as vote-counting, and has been shown to have some serious flaws (Hedges and Olkin, 1985). The proportion of studies with significant results reflects the average power of the studies to detect an effect (Hedges and Olkin, 1985). Thus, a reviewer of research studies may assume that he is examining the importance of an ecological process, but may only be examining the power of the tests used to detect it. Furthermore, this bias is not reduced as the number of studies increases. This is a severe problem in fisheries research because many studies have very low statistical power.

New approaches, based upon meta-analysis (Myers and Mertz ,1998), variance components models (Myers et al., 1999b), and Bayesian analysis (Punt and Hilborn, 1997; Hilborn and Liermann, 1998) are becoming the standard approaches to understanding population dynamics. As all ecologists know, ecological modeling of community dynamics is not rocket science, it is much harder. The use of meta-analytic approaches provides some hope, by providing a way to estimate critical biological parameters to be included in models of community dynamics.

\section{Expanding the Database}

The design and construction of the present database has taken over a decade and in extending the database, we will build upon the many lessons from this experience. One lesson that is crucial in extending the database is that an incremental approach is needed; we do not believe that we can design a successful approach the first time for most taxonomic groups. We can attempt global coverage for data from regular fisheries assessments and surveys, and coverage for selected taxa, e.g. cephalopods. To address this issue we will construct "pilot" databases for several key areas. We will test the design on these pilot studies, and then extend the database design to be able to cover the dynamics of virtually all marine species. These will be built on ongoing successful projects whenever possible. We also plan a demonstration project of marine invaders.

The worldwide spawner recruitment database has required the cooperation of scientists around the world, this support has allowed by far the largest database on marine dynamics to be assembled. This support was given because the great utility was widely recognized. We have encountered similar support for extending the level of detail and taxonomic breadth of the database.

The database was designed to allow easy linkage with other databases. We now have a semi-automated procedure to translate the existing Worldwide Spawner Recruitment database into a form used by FishBase. It could easily be linked to other databases. This will link with the OBIS project via both the georeferencing and via species identification.

The database will be built around several key ideas:

- This is an extension of the ongoing worldwide spawner recruit database.

The spawner recruitment database is already automatically transferred into FishBase (Froese et al., 1995), every year.

- There will be an extension of CephBase to include dynamics.

We have established links to coordinate databases from many national and international fisheries organizations. Key people in all regions of the US and in many countries have been contacted for their cooperation. Furthermore, the US national stock assessment coordinators supports having standard output files that could be used in the database.

- Link with existing GLOBEC databases in the U.S.

- Direct link with modeling projects, e.g. EcoPath and extensions, e.g. EcoSym (Walters et al., 1997).

- Linkage with Australian Database project for marine population data.

- Linkage with EU Data Warehouse Project for multi species database.

The worldwide spawner recruitment database is presently stored in ASCII files, which are accessible over the web, but is manipulated in the object-oriented statistical language S-PLUS. Output to FishBase is by Splus programs that produce Microsoft Access compatible data, which allow semi-automatic transfer between database formats. We plan to build and extend this approach. In particular, it is clear that database projects are developing towards object-oriented methods, e.g. the astronomical community has developed an XML language, called AML, describing various kinds of data useful in astronomy, and is aimed at being an exchange format for astronomical data, and especially metadata, over the Internet.

In summary, the worldwide stock and recruitment 
database has already played a vital role as a repository of information about the population dynamics of numerous marine species. These standardized data have been analyzed using meta-analytic techniques with great success to estimate important demographic parameters, contributing to our understanding of marine ecosystems, and human impacts upon them. Expanding the database and providing georeferenced links to the OBIS project will enable larger and more challenging problems to be confronted with adequate data.

\section{REFERENCES}

Beverton, R.J.H. and S.J. Holt, 1959: A review of the lifespans and mortality rates of fish in nature, and their relation to growth and other physiological characteristics. In: Ciba Foundation Colloquia on Ageing. G.E.W. Wolstenholme and M. O'Connor, eds., CIBA Foundation, London., 142-174.

Bradford, M.J., R.A. Myers and J.R. Irvine, 2000: Reference points for coho salmon harvest rates and escapement goals based on freshwater production. Can. J. Fish. Aquat. Sci., 57, 677-686.

Brander, K., 1994: Patterns of distribution, spawning, and growth in North Atlantic cod: The utility of interregional comparisons. ICES Mar. Sci. Symp., 198, 406413.

Casey, J.M. and R.A. Myers, 1998: Near extinction of a large, widely distributed fish. Science, 281, 690-692.

Cohen, A.N. and J.T. Carlton, 1998: Accelerating invasion rate in a highly invaded estuary. Science, 279, 555-557.

Cushing, D.H., 1971: The dependence of recruitment on parent stock in different groups of fishes. J. Cons. Int. Explor. Mer, 33, 340-362.

Dayton, P.K., S.F. Thrush, M.T. Agardy and R.J. Hofman, 1995: Environmental effects of marine fishing. Aquat. Conserv. Mar. Freshwat. Ecosyst., 5, 205-232.

Froese, R., D. Pauly, R.A. McCall and R.M. May, 1995: Fishbase: A biological database on fish (CD-ROM and user's manual). Nature, 376, 735-735.

Goldberg, E.D., 1995: Emerging problems in the coastal zone for the twenty-first century. Mar. Pollut. Bull., 31, 152-158.

Hedges, L.V. and I. Olkin, 1985: Statistical Methods for Meta-analysis. San Diego: Academic Press.

Hilborn, R. and M. Liermann, 1998: Standing on the shoulders of giants: learning from experience in fisheries. Rev. Fish Biol. Fish., 8, 1-11.

Hutchings, J.A., 2000: Collapse and recovery of marine fishes. Nature, 406, 882-885.

Hutchings, J.A. and R.A. Myers, 1994: What can be learned from the collapse of a renewable resource? Atlantic cod, Gadus morhua, of Newfoundland and Labrador. Can. J. Fish. Aquat. Sci., 51, 2126-2146.
Myers, R.A., N.J. Barrowman, J.A. Hutchings and A.A. Rosenberg, 1995: Population dynamics of exploited fish stocks at low population levels. Science, 269, 11061108.

Myers, R.A., K.G. Bowen and N.J. Barrowman, 1999a: Maximum reproductive rate of fish at low population sizes. Can. J. Fish. Aquat. Sci., 56, 2404-2419.

Myers, R.A., M.J. Bradford, J.M. Bridson, and G. Mertz, 1997: Estimating delayed density-dependent mortality in sockeye salmon, Oncorhynchus nerka; a meta-analytic approach. Can. J. Fish. Aquat. Sci., 54, 2449-2463.

Myers, R.A., Hutchings, J.A., and N.J. Barrowman, 1996: Hypotheses for the decline of the cod in the North Atlantic. Mar. Ecol. Prog. Ser., 138, 293-308.

Myers, R.A., Hutchings, J.A. and N.J. Barrowman, 1997: Why do fish stocks collapse? The example of cod in Eastern Canada. Ecol. Appl., 7, 91-106.

Myers, R.A., B.R. MacKenzie and K.G. Bowen, 1999b: Empirical models of carrying capacity, maximum reproductive rate, and species interactions using a meta-analytic approach. ICES C.M., 99/Y18, 1-21.

Myers, R.A. and G. Mertz, 1998: The limits of exploitation: a precautionary approach. Ecol. Appl., 8, Supplement 1, S165-S169.

Myers, R.A., G. Mertz, J.M. Bridson and M.J. Bradford, 1998: Simple dynamics underlie sockeye salmon (Oncorhynchus nerka) cycles. Can. J. Fish. Aquat. Sci., 55, 2355-2364.

Myers, R.A., G. Mertz and S. Fowlow, 1997: Maximum population growth rates and recovery times of Atlantic cod, Gadus morliua. Fish. Bull., 95, 762-772.

Myers, R.A., A.A. Rosenberg, P.M. Mace, N.J. Barrowman, and V.R. Restrepo, 1994: In search of thresholds for recruitment overfishing. ICES J. Mar. Sci., 51, 191-205.

Pauly, D., 1980: On the interrelationships between natural mortality, growth parameters and mean environmental temperature in 175 fish stocks. J. Cons. Int. Explor. Mer, 39, 175-193.

Pauly, D., 1995: Anecdotes and the shifting baseline syndrome of fisheries. Trends. Ecol. Evol., 10.

Punt, A. and R. Hilborn, 1997: Fisheries stock assessment and decision analysis: The Bayesian approach. Rev. Fish Biol. Fish., 7, 35-65.

Ricker, W.E., 1954: Stock and recruitment. J. Fish. Res. Bd. Can., 11, 559-623.

Ruiz, G.M., J.T. Carlton, E.D. Grosholz, and A.H. Hines, 1997: Global invasions of marine and estuarine habitats by non-indigenous species: Mechanisms, extent, and consequences. Am. Zool., 37, 621-632.

Walters, C., V. Christensen and D. Pauly, 1997: Structuring dynamic models of exploited ecosystems from trophic mass-balance assessments. Rev. Fish Biol. Fish., 7, 39-172. 